Provided for non-commercial research and education use. Not for reproduction, distribution or commercial use.

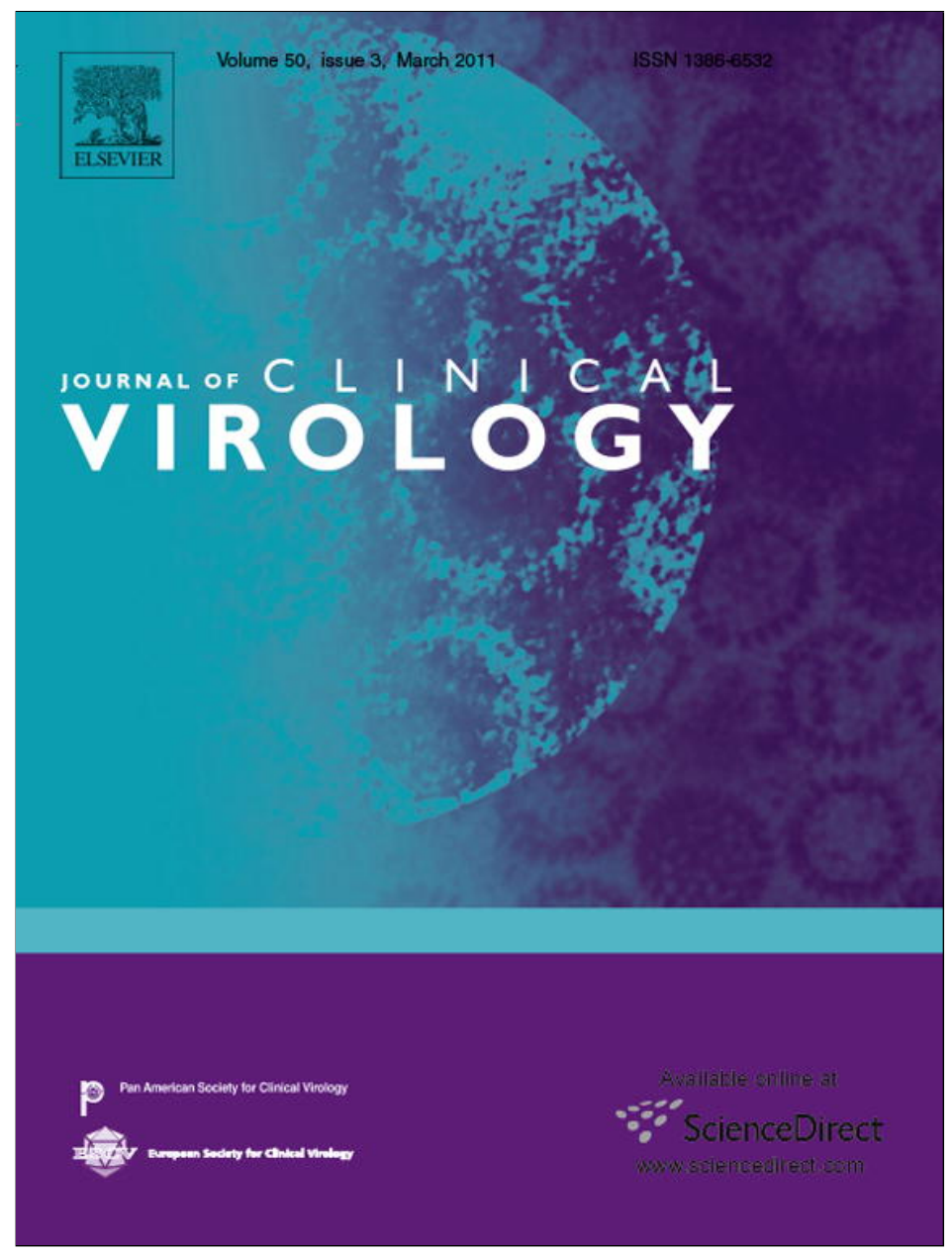

This article appeared in a journal published by Elsevier. The attached copy is furnished to the author for internal non-commercial research and education use, including for instruction at the authors institution and sharing with colleagues.

Other uses, including reproduction and distribution, or selling or licensing copies, or posting to personal, institutional or third party websites are prohibited.

In most cases authors are permitted to post their version of the article (e.g. in Word or Tex form) to their personal website or institutional repository. Authors requiring further information regarding Elsevier's archiving and manuscript policies are encouraged to visit:

http://www.elsevier.com/copyright 
Case report

\title{
A pauci-symptomatic case of documented Hantavirus (Puumala) infection in a patient under anti-TNF treatment
}

\author{
P. Moutschen, M. Bourhaba, F. Frippiat, J.B. Giot, C. Meuris, P. Léonard, M. Moutschen* \\ Department of Infectious Diseases and General Internal Medicine, CHU de Liège, University of Liège. CHU Sart-Tilman, 4000 Liège, Belgium
}

\section{A R T I C L E I N F O}

\section{Article history:}

Received 8 September 2010

Received in revised form

22 November 2010

Accepted 25 November 2010

\section{Keywords:}

Hantavirus infection

Anti-TNF therapy

Immunosuppression

\begin{abstract}
A B S T R A C T
We describe the case of an 18-yr-old male under anti-TNF treatment for Crohn's disease for more than 8 months. He developed fever and biological inflammatory syndrome without absolutely no accompanying sign or symptom or paraclinical abnormality despite extensive work-up performed in the context of his immunocompromised state. Symptoms disappeared after 10 days and a diagnosis of Puumala infection was made retrospectively on a serological basis. The case illustrates that anti-TNF treatment does not worsen the course of Puumala infection and could even be associated with a milder clinical picture.
\end{abstract}

(c) 2010 Elsevier B.V. All rights reserved.

\section{Why this case is important}

The number of cases of Hantavirus infection is sharply increasing. In Western Europe, the Puumala serotype (PUUV) is responsible for more than 10,000 cases of hemorragic fever with renal syndrome (HFRS) every year. ${ }^{1}$ Documented cases of acute PUUV infection are usually very symptomatic: renal symptoms (oliguria and anuria) occur in more than $50 \%$ of the cases and creatinin is increased in more than $90 \%$. Hemorrrhagic manifestations are uncommon but thrombocytopenia occurs in 55-70\% of the cases. Cardiac, ocular and neurological abnormalities have also been reported in more than $50 \%$ of cases. ${ }^{2,3}$ The severity of the symptoms can vary greatly between individuals but the genetic factors involved remain controversial. HLA-B27 is associated with a benign course of the disease, with minimal renal involvement. ${ }^{4}$ Conversely, the ancestral HLA-B8 DR3 haplotype has been shown to be associated with more severe forms of the infection in adults. ${ }^{5}$ This haplotype is also more frequently found in children with Puumala infection than in the general population but it is not associated with a different clinical course. ${ }^{6}$ Interestingly, the HLA-B8 DR3 haplotype is in linkage desiquilibrium with an allele of the TNF- $\alpha$ gene associated with a higher secretion of TNF- $\alpha$ (the so-called TNF-2 allele). Accordingly, Kanerva et al. found the TNF-2 allele more frequently in patients hospitalized for acute PUUV infection (42\%) than in healthy con-

\footnotetext{
* Corresponding author. Tel.: +32 43667235.

E-mail address: Michel.Moutschen@ulg.ac.be (M. Moutschen).
}

trols (15\%). ${ }^{7}$ Similar findings were reported by Makela et al. ${ }^{8}$ In a subsequent study, Makela et al. compared the severity of disease in HLA-B8DR3 negative patients with or without the TNF-2 allele and could not find any difference, suggesting that a higher TNF- $\alpha$ secretion does not by itself plays a major role in severe Puumala infection. ${ }^{9}$ Finally, Maes et al. showed that patients with the GA-238 allele of the TNF- $\alpha$ gene and considered to be low TNF producers had a more severe clinical form of Puumala Hantavirus infection than high TNF producers. ${ }^{10}$ In view of these controversies around TNF- $\alpha$ genetics in susceptibility to Puumala severe infection, we found interesting to describe the case of adult patient on anti-TNF therapy for more than eight months and developing a PUUV hantavirus infection with fever as the sole symptom

\section{Case description}

The patient is an 18 yrs. Old Caucasian male. He declared bilateral sacroiliitis in 2008. HLA-B27 was absent. At that time, he was simply treated with non-steroidal anti-inflammatory drugs. In September 2009, he developed acute terminal ileitis that led to a diagnosis of Crohn's disease after surgery. After surgery, he received a maintenance treatment with bimonthly injections of infliximab with complete resolution of articular and gastro-intestinal symptoms. Due to cutaneous reactions, infliximab was replaced by adalimumab in February 2010. The treatment was well tolerated and the patient totally asymptomatic. In May 2010, the patient presented vesperal peaks of fever between 38 and $39^{\circ} \mathrm{C}$. He had strictly no other symptoms and could normally attend his classes at high 
school. Since he was treated with anti-TNF medications, he was considered as risk for severe occult infection and a complete workup was performed. Physical examination was strictly normal. Blood analysis showed only an increased CRP at $98 \mathrm{mg} / \mathrm{L}(N<6 \mathrm{mg} / \mathrm{L})$. Leucocytes and formula were normal. Platelets were normal at $190,000 / \mu \mathrm{l}$. Urea was at $0.26 \mathrm{~g} / \mathrm{L}$ and serum creatinine at $10.5 \mathrm{mg} / \mathrm{L}$. Liver function was normal. Except for CRP, all these values were identical to those measured three months earlier on a routine analysis. Serologies for EBV and CMV were negative for IgM as well for IgG. Blood cultures were performed several times and remained negative including for mycobacteria. Chest X Ray was strictly normal as well as transesophageal echocardiogram. A PET/CT scanning was even performed and was strictly normal exceptfor a moderately increased glucose uptake in the distal ileon and ascending colon. Fever spontaneously subsided after 10 days. The diagnosis finally came out a few days later. In the context of an ongoing epidemy in our region, serum had been sent to an external reference laboratory (Institute of Tropical Medicine, Antwerp) for Hantavirus serology. IgM were positive for Puumala and Hantaan and IgG were negative for both serotypes. Four weeks later, serology was checked again and showed the appearance of IgG specifically directed against the Puumala serotype. Retrospectively, the patient recollected that three weeks before the onset of fever he had cleaned an old wood cabin in a wooded area. In view of the total absence of urinary or renal symptoms, there was unfortunately no urine analysis performed at the acute phase. When the diagnosis of hantavirus infection came out, urinary protein, $\alpha 1$-microglobulin and $\beta 2$-microglobulin excretions were measured. They were strictly normal.

Other similar and contrasting cases in the literature

To our knowledge, the clinical course of a hantavirus infection in a patient under anti-TNF or other immunosuppressive therapy has never been described before.

\section{Discussion}

Several articles have shown increased levels of proinflammatory cytokines during hantavirus infection and correlated them with the severity of the symptoms. ${ }^{11-14}$ On the other hand, it has been shown that TNF- $\alpha$ decreases the accumulation of viral nucleoproteins in Vero E6 cells infected with Sin Nombre virus. ${ }^{15}$ Accordingly, hantavirus nucleocapsid proteins antagonize the signaling pathway of TNF- $\alpha$, suggesting that this cytokine may play a role in the immune response against hantavirus. ${ }^{16}$ Our patient was only briefly exposed to contaminated aerosols and became infected while other members of his family had similar activities without clinical evidence for infection. It it therefore possible that TNF- $\alpha$ treatment has been a risk factor for infection. Nevertheless, the mild clinical course and the total absence of renal or hematologic involvement suggest that TNF- $\alpha$ is not required for the clearance of infection and might furthermore play a deleterious role in its manifestations (although we cannot formally rule out a protective genetic background despite the fact that the patient is not HLA-B27). Corticosteroids have been used to treat severe complications of hantavirus infection. ${ }^{17}$ In view of the crucial role of T cells secreting IFN- $\gamma$ in the resolution of the disease, ${ }^{18}$ amore targeted approachagainst TNF- $\alpha$ might be an option for severe hemorragic fever with renal syndrome.

\section{Funding}

All the analysis and procedures were performed in the strict context of routine clinical care and covered by the medical insurance system in Belgium.

\section{Conflict of interest}

The authors declare that there is no conflict of interest in the description of this case.

\section{References}

1. Heyman P, Vaheri A, Lundkvist A, Avsic-Zupanc T. Hantavirus infections in Europe: from virus carriers to a major public-health problem. Expert Rev Anti Infect Ther 2009; 7:205-17.

2. Makela S, Kokkonen L, Ala-Houhala I, Groundstroem K, Harmoinen A, Huhtala $\mathrm{H}$, et al. More than half of the patients with acute Puumala hantavirus infection have abnormal cardiac findings. Scand J Infect Dis 2009;41:57-62.

3. Hautala N, Kauma H, Vapalahti O, Mahonen SM, Vainio O, Vaheri A, et al Prospective study on ocular findings in acute Puumala hantavirus infection in hospitalised patients. BrJ Ophthalmol 2010, doi:10.1136/bjo.2010.185413.

4. Mustonen J, Partanen J, Kanerva M, Pietilä K, Vapalahti O, PasternackA, Vaheri A. Association of HLA B27 with benign clinical course of nephropathia epidemica caused by Puumala hantavirus. Scand J Immunol 1998;47:277-9.

5. Mustonen J, Partanen J, Kanerva M, Pietilä K, Vapalahti O, Pasternack A, Vaheri A. Genetic susceptibility to severe course of nephropathia epidemica caused by Puumala hantavirus. Kidney Int 1996;49:217-21.

6. Mustonen J, Huttunen NP, Partanen J, Baer M, Paakkala A, Vapalahti O Uhari M. Human leukocyte antigens B8-DRB1*03 in pediatric patients with nephropathia epidemica caused by Puumala hantavirus. Pediatr Infect Dis J 2004;23:959-61.

7. Kanerva M, Vaheri A, Mustonen J, Partanen J. High-producer allele of tumour necrosis factor-alpha is part of the susceptibility MHC haplotype in severe puumala virus-induced nephropathia epidemica. Scand J Infect Dis 1998;30:532-4.

8. Makela S, Hurme M, Ala-Houhala I, Mustonen J, Koivisto AM, Partanen J, et al. Polymorphism of the cytokine genes in hospitalized patients with Puumala hantavirus infection. Nephrol Dial Transplant 2001;16:1368-73.

9. Makela S, Mustonen J, Ala-Houhala I, Hurme M, Partanen J, Vapalahti O, et al. Human leukocyte antigen-B8-DR3 is a more important risk factor for severe Puumala hantavirus infection than the tumor necrosis factor-alpha(-308) G/A polymorphism. J Infect Dis 2002; 186:843-6.

10. Maes P, Clement J, Groeneveld PH, Colson P, Huizinga TW, Van Ranst M. Tumor necrosis factor-alpha genetic predisposing factors can influence clinical severity in nephropathia epidemica. Viral Immunol 2006;19:558-64.

11. Linderholm M, Ahlm C, Settergren B, Waage A, Tarnvik A. Elevated plasma levels of tumor necrosis factor (TNF)-alpha, soluble TNF receptors, interleukin (IL)-6, and IL-10 in patients with hemorrhagic fever with renal syndrome. J Infect Dis 1996;173:38-43.

12. Kanerva M, Mustonen J, Vaheri A. Pathogenesis of puumala and other hantavirus infections. Rev Med Virol 1998;8:67-86.

13. Makela S, Mustonen J, Ala-Houhala I, Hurme M, Koivisto AM, Vaheri A, et al. Urinary excretion of interleukin-6 correlates with proteinuria in acute Puumala hantavirus-induced nephritis. Am J Kidney Dis 2004;43:809-16.

14. Outinen TK, Makela SM, Ala-Houhala IO, Huhtala HS, Hurme M, Paakkala AS, et al. The severity of Puumala hantavirus induced nephropathia epidemica can be better evaluated using plasma interleukin-6 than C-reactive protein determinations. BMC Infect Dis 2010;10:132.

15. Khaiboullina SF, Netski DM, Krumpe P, St Jeor SC. Effects of tumor necrosis factor alpha on sin nombre virus infection in vitro. J Virol 2000;74:11966-71.

16. Taylor SL, Frias-Staheli N, Garcia-Sastre A, Schmaljohn CS. Hantaan virus nucleocapsid protein binds to importin alpha proteins and inhibits tumor necrosis factor alpha-induced activation of nuclear factor kappa B. J Virol 2009;83:1271-9.

17. Seitsonen E, Hynninen M, Kolho E, Kallio-Kokko H, Pettila V. Corticosteroids combined with continuous veno-venous hemodiafiltration for treatment of hantavirus pulmonary syndrome caused by Puumala virus infection. Eur J Clin Microbiol Infect Dis 2006;25:261-6.

18. Wang M, Wang J, Zhu Y, Xu Z, Yang K, Yang A, et al. Cellular immune response to Hantaan virus nucleocapsid protein in the acute phase of hemorrhagic fever with renal syndrome: correlation with disease severity. J Infect Dis 2009; 199:188-95. 